\title{
SYPHILIS ANTIGEN FROM THE SOYA BEAN
}

\author{
BY
}

\author{
JOHN S. STEVENSON
}

From the Department of Pathology, Stobhill Hospital, Glasgow

The non-specificity of "syphilis antigen" has been the subject of much speculation from the time it was first demonstrated that substances which exerted an antigenic effect in complement-fixation tests for syphilis could be extracted from normal mammalian tissues (Weygandt, 1907 ; Landsteiner and others, 1907). Further proof of the nonspecificity of these " antigenic" substances has been evidenced by their extraction from such diverse materials as fish (Neymann and Gager, 1917), scallops (Sanderson, 1928), and various microorganisms, including the $M$. tuberculosis and $B$. proteus X19 (Weil, 1941). Thus it is assumed that "syphilis antigen" is widely distributed in nature, and it is not surprising to find that it has been shown to be present in vegetable tissue : Heinlein (1912) described an antigen which he had extracted from potatoes : the antigenic reactions of peas, beans, and corn were investigated by Tribondeau (1913), who found that extracts of peas proved satisfactory ; Walker (1917) also obtained good results with peaantigen ; a large number of plants and seeds were investigated by Weiss (1923), who found that extracts made from olives añ coconuts contained relatively large amounts of "syphilis antigen."

In view of the generally accepted belief that syphilis antigen is similar chemically to the phosphatides, vegetable material containing even moderate amounts of phosphatide might be expected to yield an antigen of fair quality. Thus the relatively high phosphatide content of the soya bean (Maclean and Maclean, 1927) suggested the use of this versatile substance as a source of antigen for use in tests for syphilis. To investigate this possibility, various extracts made from commêrcial soya flour and the whole bean were tested for their ability to react with syphilitic sera : the extractions were carried out in several different ways in order to find the most promising method.

The antigenic activities of these somewhat empirical extracts were examined by substituting them for the Kahn antigen normally employed to make the reagent of a modified version of the
Laughlen test which has been found extremely reliable (Stevenson, 1948).

The use of the Laughlen test in this way may call for some comment. The main advantage was that the various tests to which the soya extracts were subjected could be carried out rapidly and with a minimum 'of apparatus, and as the particular modification mentioned above had been in routine use for some time before the present investigation was undertaken, there was offered a standard of comparison by which the activity of the soya extracts could be compared directly with that of the Kahn antigen they replaced. The tests were conducted in parallel with the Wassermann (Wyler, 1929, 1932) and Kahn reactions.

\section{Procedure \\ THE Flour ExTRACTS}

1. The method of extracting Kahn antigen from dried beef heart was applied to soya flour, $25 \mathrm{~g}$. of which were extracted successively with $100,75,75,75 \mathrm{ml}$. of pure ether. The flour was then dried and weighed and extracted for three days at room temperature with 95 per cent. ethyl alcohol in the proportion of $5 \mathrm{ml}$. of alcohol per $1 \mathrm{~g}$. of flour. The alcohol was then filtered off, chilled at $4^{\circ} \mathrm{C}$. overnight, filtered again, and cholesterolized in the usual manner $(6 \mathrm{mg}$. of cholesterol per ml. of extract).

2. As for (1), with the exception that the alcohol extraction was carried out at boiling point $\left(80^{\circ} \mathrm{C}\right.$.) for one hour instead of room temperature for three days.

3. $50 \mathrm{~g}$. of the flour were extracted for three days at $4^{\circ} \mathrm{C}$. with $200 \mathrm{ml}$. acetone, which was thereafter removed by filtration. The flour was then thoroughly dried and extracted with boiling alcohol as in (2), the extract being filtered clear and cholesterolized as before.

4. $50 \mathrm{~g}$. of the flour were extracted for seven days at room temperature with $200 \mathrm{ml}$. of absolute ethyl alcohol, which was then filtered off and cholesterolized.

5. $50 \mathrm{~g}$. of the flour were extracted for three days at room temperature with $200 \mathrm{ml}$. of petroleum ether, which was then filtered off and evaporated at $37^{\circ} \mathrm{C}$. for four days. No odour of petroleum ether could then be detected, and the volume of the extract, which had become thick and syrupy, was reduced to $27 \mathrm{ml}$. This "syrup" was poured into $100 \mathrm{ml}$. of absolute ethyl 
alcohol, shaken, and the mixture left aside for two hours. A whitish deposit formed : this was removed by filtration and the alcoholic extract cholesterolized.

6. As for (5), with the exception that the flour was extracted three times with $150 \mathrm{ml}$. of ether before making the petroleum ether extraction.

7. As for (5), with the exception that the flour was extracted with acetone (as in (3) ) before making the petroleum ether extraction.

\section{The Whole-Bean Extracts}

The beans were reduced to a coarse powder by grinding in a meat mincer fitted with fine cutters. Seven extracts were made in exactly the same way as the flour extracts, and tests were conducted with the subsequent reagents in parallel with those carried out with the flour extracts. Since the whole bean contains a high proportion of an oil rich in phosphatides (Markley and Goss, 1944), it was expected that these extracts would show appreciable antigenic activity.

\section{Results}

Table I shows the results obtained with a reagent made from Extract 1 . The reagent was insensitive when first made, but gave fairly accurate readings when about thirty to thirty-six hours old, thereafter becoming too sensitive. The same ten sera were tested against a reagent made from Extract 2, and the results, though similar, were much more distinct than those obtained with the first reagent and the sensitivity was fully developed when it was eighteen hours old. Accordingly, Extract 2 was tested on a larger scale. Another reagent was made from it, left aside for eighteen hours, and then tested with 143 sera whose reactions to the Wassermann and Kahn tests were known (Table II). The sera were divided into two groups, "diagnostic" and "treated," and it is seen that while perfectly reliable results were obtained with the first group, several discrepancies occurred with the sera from treated cases. This finding is of interest, since the original modified Laughlen test also gave irregular results with similar specimens.

Reagents made with the remaining extracts $(3,4$, 5 , 6, and 7) were examined similarly. Only one, No. 6, gave a good antigenic response ; poor results were obtained with 5 and 7 , and no activity was found in 3 and 4 . In view of the good results obtained with Extract 6, further trials were carried out as was done with Extract 2; the findings were similar, that is, the tests with the "diagnostic" specimens compared very favourably with the Wassermann and Kahn results, but marked discrepancies were found in the " treated " group.

TABLE I

THE REACtivity OF A "LAUghlen" REAGENT MADE From EXTRACT No. 1

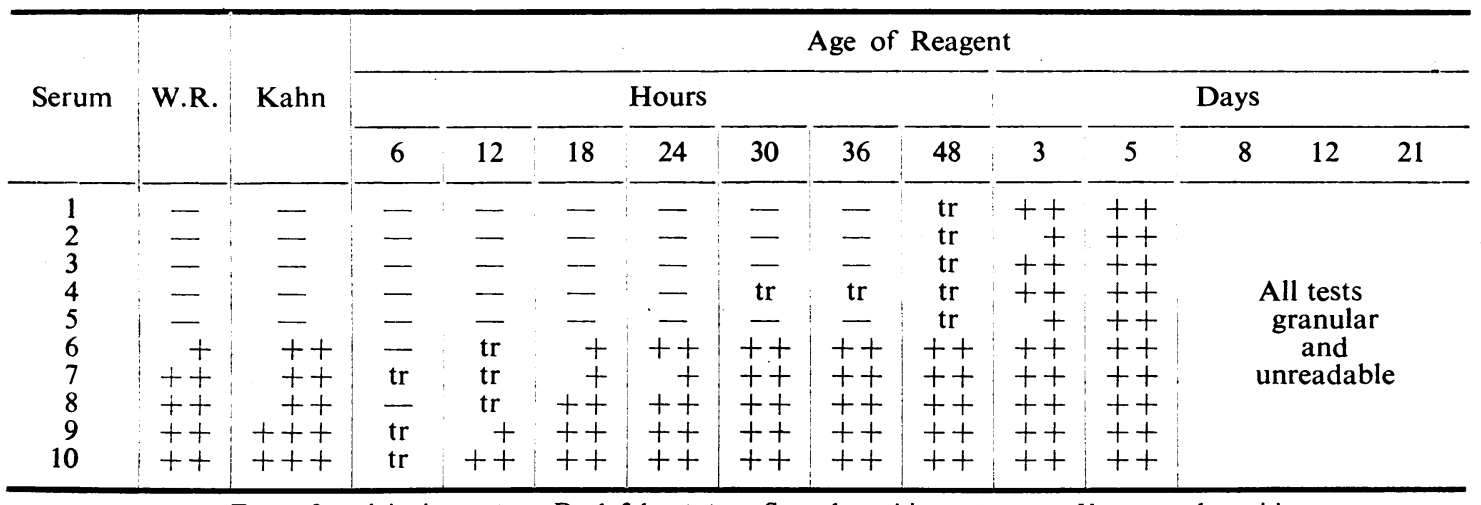

$\operatorname{tr}=$ Trace of precipitation. $\quad+=$ Doubtful. $++=$ Strongly positive. $+++=$ Very strongly positive.

TABLE II

ONE HUNDRED AND FORTY-THREE ROUTINE SERA TESTED IN PARALLEL WITH THE WASSERMANN REACTION, KAHN TEST, AND A REAGENT MADE WITH EXTRACT NO. 2

\begin{tabular}{|c|c|c|c|c|c|c|c|c|c|c|c|c|c|}
\hline \multirow[b]{2}{*}{$\begin{array}{l}\text { No. of sera } \\
\text { Wassermann } \\
\text { Kahn } \\
\text { R.E. } 2 \quad \ldots\end{array}$} & \multirow[b]{2}{*}{$\begin{array}{l}\cdots \\
\cdots \\
\cdots\end{array}$} & \multirow[b]{2}{*}{$\begin{array}{l}\ldots \\
\ldots \\
\ldots \\
\ldots\end{array}$} & 45 & \multicolumn{2}{|c|}{ Diagnostic } & & \multicolumn{4}{|c|}{ Treated } & & \multirow[b]{2}{*}{$\begin{array}{r}1 \\
+ \\
++ \\
-\end{array}$} & $\frac{\text { Total }}{143}$ \\
\hline & & & $\frac{45}{-}$ & $\frac{3}{-}$ & $\begin{array}{c}4 \\
++ \\
+++ \\
+++\end{array}$ & $\frac{54}{-}$ & $\begin{array}{l}16 \\
++ \\
++ \\
++\end{array}$ & $\begin{array}{l}2 \\
++ \\
++\end{array}$ & $\begin{array}{c}3 \\
+ \\
++ \\
++\end{array}$ & $\begin{array}{l}1 \\
+ \\
-\end{array}$ & $\begin{array}{l}14 \\
++ \\
++\end{array}$ & & 143 \\
\hline
\end{tabular}

R.E. $2=$ Reagent made with Extract $2 .+=$ Doubtful. $++=$ Strongly positive. $+++=$ Very strongly positive. 
The results of the tests with the whole bean extracts proved disappointing and did not support the previous presumption that the oil content of the bean would produce extracts of fair antigenic activity. Without exception, the reagents made with the whole bean extracts gave no indication of reacting with syphilitic sera.

Various changes in the method of making the reagents did not produce better results.

\section{Discussion}

Several points of interest arise from this investigation. The first is the demonstration that ordinary soya flour contains a substance which reacts like "syphilis antigen." It may be presumed that this substance is similar to the active part of the antigens extracted from such tissues as mammalian heart. Secondly, the most promising method of extraction appears to be a preliminary treatment with ether followed by boiling alcohol (vide Extracts 2 and 6) : it is suggested that antigens for precipitation tests in general might be improved by the use of this boiling alcohol process. Thirdly, soya flour is so plentiful and inexpensive that it gives new possibilities for the investigation of many problems concerning the structure of syphilis antigen, and although the antigen produced by the present methods was of moderate quality only, it seems probable that the development of more elaborate procedures would succeed in giving extracts of high antigenic activity.

Contrary to what had been expected, the extracts made from the whole bean proved useless as antigens. Since soya flour is produced from the whole bean when the latter is crushed during the removal of soya oil, it is presumed that this oil is the factor which prevented the extraction of the antigenic substances by the methods described.

Here again it is possible that this difficulty could be overcome by more elaborate methods which would facilitate the release of good-quality antigen.

\section{Summary}

By an examination of various extracts it has been established that commercial soya flour contains syphilis antigen or some similar substance. Although the whole soya bean must also contain this substance, it was not possible to demonstrate its presence by the methods employed.

This investigation was carried out in the Central Laboratory, Public Health Department, Glasgow. I wish to express my thanks to Dr. R. D. Stuart, lately City Bacteriologist, Glasgow, for his interest and advice.

\section{REFERENCES}

Heinlein, F. (1912). Diss. Munchen. (Quoted by Weiss, 1923.)

Kahn, R. L. (19े28). "The Kahn Test-a Practical Guide." Baillière, Tindall, and Cox. London.

Landsteiner, K., Müller, R., and Pötzl, C. (1907). Wien. Klin., Wschr., 20, 1565.

Laughlen, G. F. (1935). Canad. med. Ass. J., 33, 179.

-(1938). Canad. J. publ. Hlth., 29, 396.

- (1944). Amer. J. clin.Path., 14, Tech. Sect., p. 109. (1946). Brit. J. vener. Dis., 22, 15.

Maclean, H., and Maclean, I. S. (1927). “Lecithin and Allied Substances. The Lipins." Longmans, Green and Co. Ltd.; London.

Markley, K. S., and Goss, W. H. (1944). "Soybean Chemistry and Technology." Chemical Publishing Co. New York.

Neymann, C. A., and Gager, L. T. (1917). J. Immunol., 2,573 .

Sanderson, E. S. (1928). Amer. J. Syph., 12, 136.

Stevenson, J. S. (1948). J. clin. Path., 1, 162.

Tribondeau, L. (1913). C. R. Acad. Sci., Paris, 156, 340.

Walker, R. M. (1917). J. Path. Bact., 21, 184.

Weil, A. J. (1941). Bact. Rev., 5, 294.

Weiss, E. (1923). J. Lab. clin. Med., 8, 476.

Weygandt, W. (1907). Munch, med. Wschr., 54, 1557.

Wyler, E. J. (1929). M. R. C. Spec. Rep. Series No. 129. London.

(1932). Ministry of Health, Report on Public

Health and Medical Subjects. No. 67. London. 